\title{
S.O.S. por la infraestructura deportiva y recreativa de la RACS
}

Roberto Fonseca

Una investigación sobre la infraestructura deportiva y de recreación en cinco municipios de la Región Autónoma del Caribe Sur (RACS), reveló que hay alrededor de 73 instalaciones y que el $95 \%$ de las mismas urge de rehabilitación, ya que se encuentran entre un estado de "regular" hasta "malo" debido a la falta de asignación presupuestaria por parte de las autoridades del gobierno regional de la RACS y de las alcaldías de Bluefields, Corn Island, Laguna de Perlas, Kukra Hill y la Desembocadura del Río Grande.

La investigación, promovida por el Programa Educación para el Éxito (EduÉxito), ejecutado por la Fundación para el Desarrollo de la Costa Atlántica de Nicaragua (FADCANIC), estimó entre sus hallazgos que se requiere de una inyección de recursos por el orden de los US\$3.1 a 5.6 millones para la rehabilitación y equipamiento adecuado de decenas de instalaciones deportivas y culturales que se encuentran prácticamente en el abandono.
En la investigación se evaluaron las condiciones físicas y de seguridad de las canchas de baloncesto, futbol, casas de cultura, gimnasios, campos deportivos libres, así como los equipos con que cuentan estos centros. Se determinó que la mayoría de las que se encuentran en regulares o en malas condiciones pertenecen y son administradas por el sector público (gobiernos municipales), y se advierte que por carecer de infraestructura mínima y de implementos deportivos se están convirtiendo en potenciales focos de consumo de drogas y de actividades delincuenciales.

\section{Un sinfín de carencias}

El estudio se llevó a cabo durante el mes de marzo del 2013 mediante un proceso de abordaje que incluyó la investigación in situ, el acceso a las fuentes directas documentales y personales, así como fuentes indirectas disponibles, priorizando una metodología participativa de construcción investigativa y propositiva.

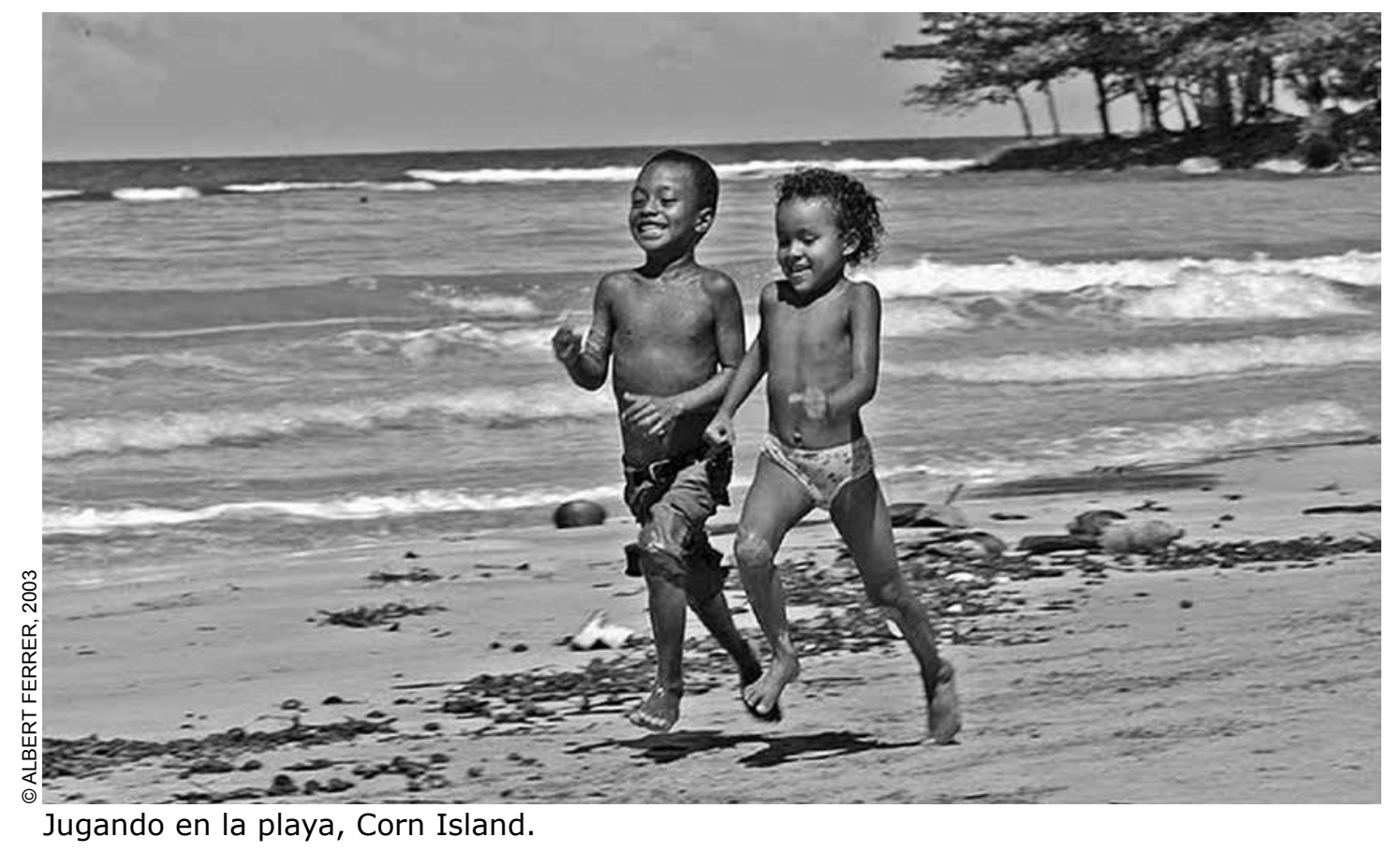


Cuadro 1. Infraestructuras deportivas y recreativas en cinco municipios costeros de la RACS

\begin{tabular}{lccccccc}
\hline Municipios & Gimnasio & $\begin{array}{c}\text { Cancha } \\
\text { multiuso }\end{array}$ & $\begin{array}{c}\text { Campos } \\
\text { deportivos }\end{array}$ & Estadios & Parques & $\begin{array}{c}\text { Centros } \\
\text { culturales }\end{array}$ & Total \\
\hline Bluefields & 3 & 16 & 2 & 3 & 2 & 2 & 28 \\
Kukra Hill & 1 & 2 & 1 & 1 & 1 & 1 & 7 \\
Laguna de Perla & 1 & 5 & 4 & 1 & 1 & 2 & 14 \\
$\begin{array}{l}\text { Desembocadura de Río } \\
\text { Grande }\end{array}$ & 0 & 2 & 3 & 1 & 2 & 1 & 9 \\
Corn Island & 1 & 1 & $\mathbf{7}$ & 2 & 3 & 1 & 15 \\
\hline Totales & $\mathbf{6}$ & $\mathbf{2 6}$ & $\mathbf{1 7}$ & $\mathbf{8}$ & $\mathbf{9}$ & $\mathbf{7}$ & $\mathbf{7 3}$ \\
\hline
\end{tabular}

Fuente: Elaboración propia basada en datos de FADCANIC 2013. Alvarado, E. Análisis de las necesidades de infraestructura y equipamientos deportivos y recreativos en cinco municipios de la Región Autónoma del Caribe Sur.

En los cinco municipios del estudio, se identificaron y ubicaron con ayuda de GPS un total de 73 infraestructuras deportivas y de recreación, ubicándose la mayoría de estas en dos municipios: Bluefields y Corn Island.

Además de las 73 instalaciones deportivas y culturales, se identificaron y ubicaron cinco oficinas de atención a los jóvenes, siete centros de cultura y cuatro playas en los municipios costeros, donde se recrea la juventud pese a que éstas carecen de instalaciones para la práctica de deportes de playa.

Aunque la cifra podría parecer significativa, la infraestructura deportiva y recreativa resulta insuficiente para que la juventud caribeña pueda divertirse, hacer deporte y fomentar la cultura, ya que el $95 \%$ se encuentra en mal estado o mal equipadas. Es común que la mayoría por ejemplo no cuenten con luminarias, con muros perimetrales de seguridad, con implementos deportivos o culturales, con vigilantes, con horarios extendidos, etcétera, pese a que de acuerdo a los informes de Desarrollo Humano del Programa de las Naciones Unidas para el Desarrollo (PNUD), la población infantojuvenil en esta zona del país supera el $60 \%$ del total.

En principio se debe comprender que los centros deportivos y de recreación son espacios públicos y privados que fomentan la promoción y orientación integral de las personas y en particular de jóvenes y adolescentes. En estos se desarrollan o se deberían desarrollar acciones lúdicas que fomenten habilidades para la vida como la educación física, la competición sana, aprendizajes de arte y cultura, liderazgo y desarrollo personal.

Los resultados de la investigación destacan que el béisbol es la disciplina deportiva que más se practica en los cinco municipios del estudio. Le siguen el futbol y en otros casos el softbol.

\section{Cuadro 2. Actividades que se realizan en infraestructuras deportivas y recreativas de cinco municipios costeros de la RACS}

\begin{tabular}{|c|c|c|c|c|c|}
\hline Gimnasio & Cancha Multiuso & Campos deportivos & Estadios & Parques & Centros de cultura \\
\hline Baloncesto & Baloncesto & Futbol & Beisbol & Futbol sala & $\begin{array}{l}\text { Eventos artísticos y } \\
\text { recreativos }\end{array}$ \\
\hline Futbol sala & Futbol sala & Beisbol & Futbol & Conciertos & Gastronomía, \\
\hline Volibol & Volibol & Softbol & Atletismo & Concentraciones & Exposiciones de artesanía \\
\hline \multirow[t]{2}{*}{$\begin{array}{l}\text { Eventos recreativos } \\
\text { (conciertos) }\end{array}$} & Eventos recreativos & Educación física & Conciertos & & Recitales de poesía \\
\hline & Educación Física & Atletismo & & & Talleres de pintura \\
\hline
\end{tabular}

Fuente: Elaboración propia basada en datos de FADCANIC 2013. 
La investigación también determinó que a las instalaciones deportivas acuden a diario un buen número de usuarios y que la mayoría de los jóvenes llegan por la tarde. Las canchas deportivas multiusos son empleadas para practicar baloncesto, fútbol sala y volibol.

Los centros escolares estatales y subvencionados también cuentan con infraestructura deportiva pero esta solo es utilizada durante la jornada educativa, en las clases de Educación Física y en el recreo. Los fines de semana estos centros escolares permanecen cerrados y de forma general, en las zonas rurales muy poco se practica el deporte de recreación escolar debido a las carencias de materiales deportivos y por la falta de organización.

Los campos deportivos son accesibles todos los días de la semana y se emplean para jugar fútbol y beisbol, pero no cuentan con el equipamiento necesario.

Los resultados indican que los estadios municipales que prestan buenas condiciones, solamente son utilizados para jugar los fines de semana o cuando hay ligas de beisbol.

Es importante destacar que el ingenio de la juventud y de la niñez permite que se recreen pese a que no cuentan con material deportivo. A falta de materiales elaboran pelotas con calcetines y se organizan en grupos para solicitar apoyo

\section{Cuadro 3. Preferencias deportivas y estimaciones de reparación de instalaciones deportivas y recreativas de cinco municipios costeros de la RACS}

\begin{tabular}{|c|c|c|c|}
\hline \multirow{2}{*}{ Municipio } & \multirow{2}{*}{ Deportes de preferencia } & \multicolumn{2}{|c|}{ Costos estimados* } \\
\hline & & Máximo & Mínimo \\
\hline Bluefields & $\begin{array}{l}\text { Béisbol, futbol, softbol, } \\
\text { baloncesto, atletismo, boxeo, } \\
\text { atletismo, volibol }\end{array}$ & $2,427,000$ & $1,365,000$ \\
\hline Kukra Hill & Béisbol, futbol & 330,000 & 175,000 \\
\hline $\begin{array}{l}\text { Laguna de } \\
\text { Perlas }\end{array}$ & $\begin{array}{l}\text { Béisbol, softbol, baloncesto, } \\
\text { volibol, }\end{array}$ & 690,000 & 410,000 \\
\hline $\begin{array}{l}\text { Desembocadura } \\
\text { de RíoGrande }\end{array}$ & Béisbol, softbol & $1,160,000$ & 641,000 \\
\hline Corn Island & $\begin{array}{l}\text { Béisbol, softbol, baloncesto, } \\
\text { volibol }\end{array}$ & $1,067,000$ & 575,000 \\
\hline
\end{tabular}

* Los costos de rehabilitación asignados a cada una de las infraestructuras recreativas son las estimaciones para llegar a las condiciones básicas que se requiere para la atención de los usuarios. Los planes de inversión municipal PIA y PIM no contemplan en sus asignaciones recursos suficientes para el mejoramiento de las infraestructuras.

Fuente: Elaboración propia basada en datos de FADCANIC 2013. para equipamientos de materiales deportivos, así como patrocinio para formar ligas de corta duración.

\section{Costos de rehabilitar centros}

La Ley de Deporte (Ley 522), aprobada el 24 de junio de 2005 , orienta a las alcaldías a promover y a desarrollar las actividades deportivas, recreativas y comunitarias de la población en su territorio; e insta a incluir en sus planes de trabajo acciones que propicien y garanticen el soporte económico necesario para el desarrollo deportivo, recreativo y comunitario. Sin embargo, la realidad indica que el nulo presupuesto asignado por las municipalidades y las instituciones encargadas de velar por la juventud $\mathrm{y}$ el deporte, ha provocado el deterioro reflejado en los resultados del estudio.

Este deterioro abarca todos los aspectos. Los hallazgos reflejan que la infraestructura deportiva y de recreación adolece de equipamiento de materiales básicos, de techos, de graderías, de agua y saneamiento, de sistemas de seguridad y de luminarias, entre otros.

Se estima que en promedio el costo de reparación de cada infraestructura deportiva y de recreación oscila entre US $\$ 30,000$ y US $\$ 50,000$. La construcción de un gimnasio podría costar entre US $\$ 300,000$ y US $\$ 500,000$. Ese valor está en dependencia del municipio, de su ubicación geográfica y de su tamaño.

Un riesgo latente, que ya se verifica en algunas localidades, es que los centros se conviertan en lugares oscuros e inseguros y, por tal, que sean utilizados por bandas de delincuentes para practicar acciones ilegales como venta y consumo de drogas, violaciones y asaltos.

Es urgente que las municipalidades incluyan dentro de sus planes de inversión pública los costos por mantenimiento, rehabilitación y reemplazo de las infraestructuras deportivas y de recreación. Igual de importante es la elaboración de proyectos que estén a la disposición de las organizaciones gubernamentales y no gubernamentales para la búsqueda de financiamiento dentro de convenios estratégico de colaboración, en el que queden claras las reglas de las competencias institucionales.

Es de especial importancia realizar campañas de sensibilización permanentes dirigidas a la 
población usuaria para que comprenda la importancia del cuido de las infraestructuras deportivas y de recreación.

\section{Empirismo en entrenadores y autoridades deportivas}

A la escasez y debilidad de la infraestructura se suma la falta de capacitación y el alto nivel de empirismo en la educación deportiva. La experiencia indica que en las zonas rurales el maestro de Educación Física apenas tiene aprobado el plan básico (tercer año de secundaria), lo que hace indicar que ni siquiera es docente normalista.

Los resultados del informe también hacen hincapié en el hecho que, si bien la Bluefields Indian \& Caribbean University (BICU) ofrece la carrera de docencia en educación física, en la región no hay ningún instituto que forme a los técnicos en educación física o en los distintos deportes que se practican en la región y por esa causa hay desconocimiento sobre cómo asesorar a un atleta. Sin embargo la investigación destaca el plus esfuerzo realizado por las y los maestros, quienes no cuentan con el equipamiento y tratan de satisfacer la alta demanda.

Por otra parte, según se indica en el informe del estudio, "los representantes de las federaciones deportivas muchas veces son líderes comunales, quienes han sido escogidos pese a que no han practicado una disciplina deportiva y que no cuentan con una preparación académica". Usualmente son designados por su posición social o por su amor al deporte y actúan en base a experiencia o intuición, señala el informe del estudio.

Los resultados también hacen énfasis en la importancia de que en los municipios estudiados funcionen las organizaciones o federaciones deportivas, a fin de impulsar el desarrollo del deporte y la recreación sana que estimule un ambiente competitivo entre las diferentes disciplinas.

En la actualidad las federaciones deportivas no están funcionando a su capacidad porque carecen de presupuesto y de personal técnico calificado. Se organizan voluntariamente y cada quien asume el pago de la inscripción de sus equipos, de los árbitros y del avituallamiento, una situación que limita y desmotiva a la juventud.

\section{Bluefields: condiciones mínimas, mayor riesgo}

Los resultados del estudio fueron divididos por municipio, de suerte tal que se tiene información detallada de la situación, que en muchos casos varía de acuerdo a las necesidades y características propias de cada zona.

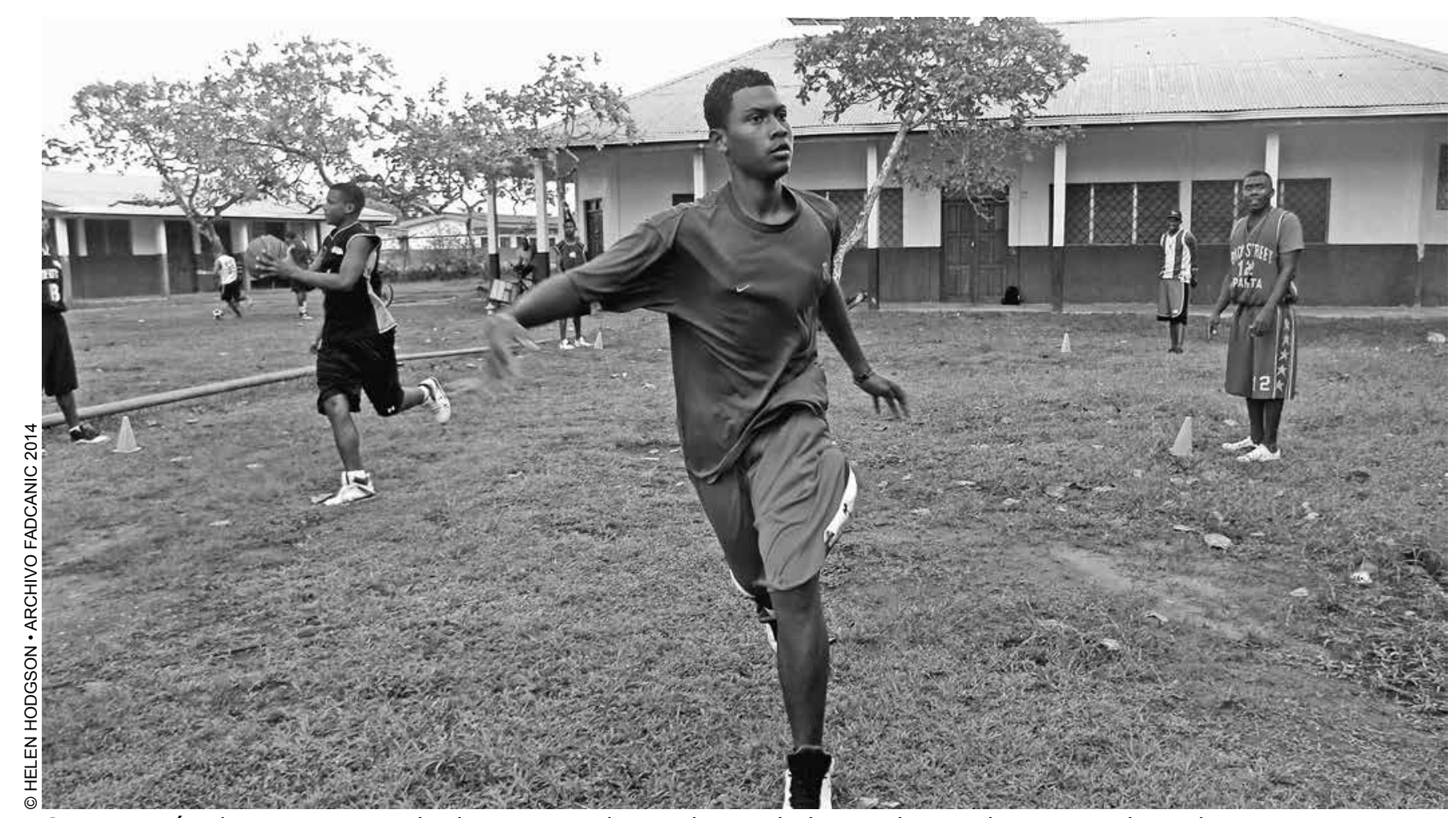

Capacitación de instructores de deportes en la Academia de la Excelencia de Laguna de Perlas. 
El municipio de Bluefields es la cabecera de la Región Autónoma Caribe Sur (RACS). La ciudad está ubicada a 383 kilómetros al oriente de Managua posee una superficie de $4,774.75 \mathrm{~km}^{2}$.

La población total de Bluefields según las proyecciones del Instituto de Información para el Desarrollo (INIDE, 2008) para el año 2014 es de 49, 292 habitantes de los cuales 25,536 son mujeres (52\%). Según los datos del censo de 2005 , del total de hombres, $41 \%$ son menores de quince años. En el caso de las mujeres, del total, 37\% se encuentran en el mismo rango (menores de quince años).

El estudio indica que cuenta con 28 infraestructuras deportivas de recreación ubicadas en diferentes puntos del municipio, principalmente en la cabecera municipal.

Los lugares de recreación deportiva son visitados frecuentemente por jóvenes. La mayor parte de estos están localizados en los centros escolares y apenas el 5\% está en excelente estado, el 60\% califica como "bueno", el 30\% como "regular" y el 5\% restante presenta "malas" condiciones y aun así está siendo utilizado.
Cabe indicar que se considera en "buen estado" cuando cuenta con las condiciones básicas de la infraestructura, como el piso, los aleros, las graderías y enmallados, entre otras. "Regular estado" es cuando posee algunas de las condiciones básicas elementales en malas condiciones y "mal estado" cuando las condiciones básicas están deterioradas y en abandono.

En Bluefields hay dos estadios de béisbol que presentan serias deficiencias porque no tienen luminarias, razón por la que es imposible que se realicen juegos nocturnos. De las 28 infraestructuras, resaltan 16 canchas multiusos. Estos son locales no techados, utilizados para practicar diversas disciplinas deportivas. El estudio revela que 18 centros, entre gimnasios y canchas multiusos, son los que reciben más afluencia de deportistas.

En su mayoría, la infraestructura blufileña carece de elementos básicos por la falta de mantenimiento, develando así el olvido en el que han permanecido estos sitios. Por esa causa se hace necesaria la inclusión de estos requerimientos en los planes de Inversión Pública y en los Planes Multianuales del municipio. Es preciso, asimismo, que la municipalidad asuma su rol, que realice gestiones ante la cooperación o bien que establezca sinergias o

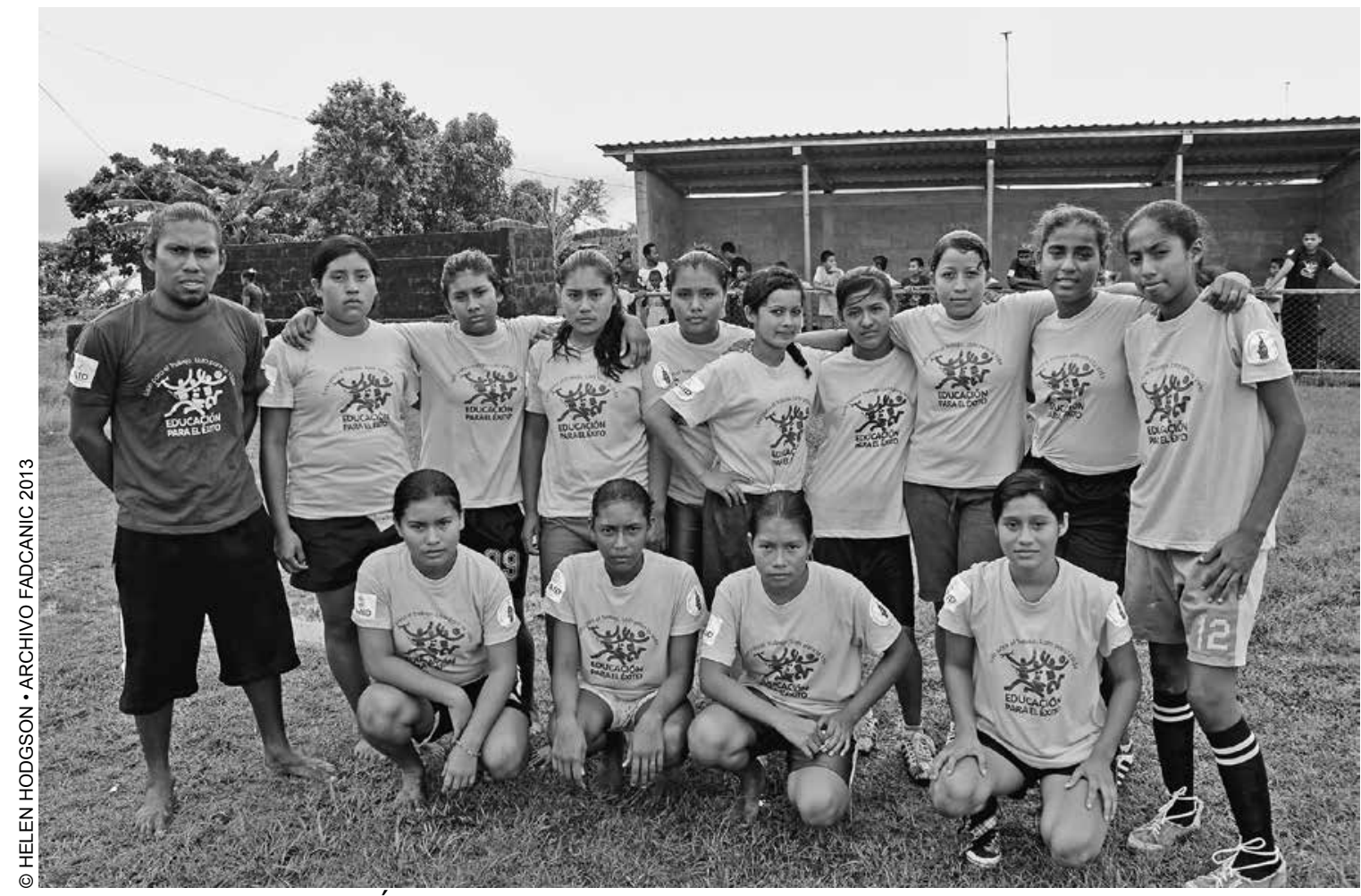

Equipo de futbol de EduÉxito integrado por jugadoras de Bluefields y Rama Key. 
complementariedades con otras instituciones a fin de garantizar el establecimiento y fortalecimiento de las infraestructuras deportivas de recreación.

El estudio confirmó que de las 28 infraestructuras se hace necesario el reemplazo de dos de éstas: el estadio Glorias Costeñas, cuya vida útil ya acabó y cuyo costo de renovación se calcula entre US $\$ 35,000$ y US $\$ 70,000$; y la Cancha de Básquet Sector \#4 en El Bluff, que podría costar entre US $\$ 20,000$ y US $\$ 25,000$.

Las canchas multiusos carecen de graderías, de materiales deportivos, de muros perimetrales, de bancas, de depósitos de basura y de baños, entre otros. En algunos casos no tienen sistema de aguas negras, en otros precisan de tableros, de techos y de bancas. Hay centros que necesitan mejoramiento del sistema eléctrico, de botiquines de primeros auxilios y extinguidores de fuego.

En los parques hacen falta servicios higiénicos, grifos y depósitos de basura. Una de las deficiencias más generalizadas en los centros deportivos y de recreación existentes en Bluefields es la falta de seguridad. En total, la rehabilitación de la infraestructura deportiva y de recreación de este municipio podría costar entre US\$1.3 millones y US\$2.4 millones.

Entre los hallazgos destaca también que una gran parte de la infraestructura deportiva que se encuentra sin luminarias y sin muros perimetrales, ya se utiliza como expendio de drogas, o bien, como un lugar de reunión de consumidores de estupefacientes. Debido a esto, también se han convertido en escenarios de delitos, entre estos, violaciones.

Para conocer en detalle los requerimientos de las infraestructuras deportivas y de recreación identificadas en el municipio de Bluefields ver al final del artículo, en Anexos, la Tabla 1.

\section{En Kukra Hill: mitad y mitad}

El municipio de Kukra Hill se encuentra ubicado a 30 kilómetros de Bluefields. Posee una extensión territorial de 1,262 $\mathrm{Kms}^{2}$ y una población estimada en 8, 789 habitantes. Proyecciones poblacionales al 2014 sitúan la población del municipio en 9,645 habitantes de los cuales el $49 \%$ son mujeres. En términos etarios, del total de la población registrada en el censo de 2005 , el $41 \%$ es menor de 15 años y de este total, el $20 \%$ son mujeres.

En el estudio fueron identificadas siete estructuras deportivas y de recreación, entre ellas un estadio. La mayoría está en los centros escolares. "El 50\% está en regular estado, el $40 \%$ en buen estado y el $10 \%$ en excelente estado", precisan las conclusiones.

Contrario a la situación de los estadios blufileños, en Kukra Hill el estadio municipal tiene luminarias, lo que permite la realización de juegos nocturnos. Dicho centro deportivo tiene capacidad para 3,000 personas.

Asimismo hay un campo de futbol en regular estado en el que caben 800 personas, un gimnasio multiusos que también está en regular estado y, entre otros, un campo alterno de béisbol que está en mal estado.

Cabe mencionar que en este municipio hay una Casa de Cultura con capacidad para 200 personas que es visitada todos los días por sus habitantes, debido a que presta las condiciones básicas para desarrollar actividades culturales y recreativas. Asimismo, hay un parque con una cancha deportiva.

La falta de luminarias en las infraestructuras deportivas -con excepción del estadio municipal- es uno de los problemas más sentidos en Kukra Hill. Como en todos los casos, la falta de mantenimiento para impulsar el deporte y la sana recreación ha provocado que estos centros se vuelvan vulnerables e inseguros por las noches. Persiste la falta de equipos, de baños públicos, de muros perimetrales; hay problemas en los techos, en el alambrado, en el sistema eléctrico y en uno de los casos faltan gradas.

En este municipio también, el estudio ha encontrado que, "los centros de recreación deportivas se encuentran en riesgo de mayor deterioro debido que no cuentan con un presupuesto asignado por las municipalidades y por las autoridades regionales y tampoco está plasmado en las estrategias para el desarrollo del municipio".

Entre los riesgos que la población de Kukra vislumbra por el abandono de estos sitios, está en que se conviertan en sitios para asaltar, para violar, para consumir drogas, como escondites de delincuentes y como lugar de citas de parejas que no miden el peligro. Por eso como soluciones se plantea:

- capacitar docentes de educación física y organizar las estructuras de los centros;

- impulsar una auditoría social en el municipio;

- capacitar en valores, liderazgo y gestión de recursos;

- sensibilizar sobre la drogadicción; y 

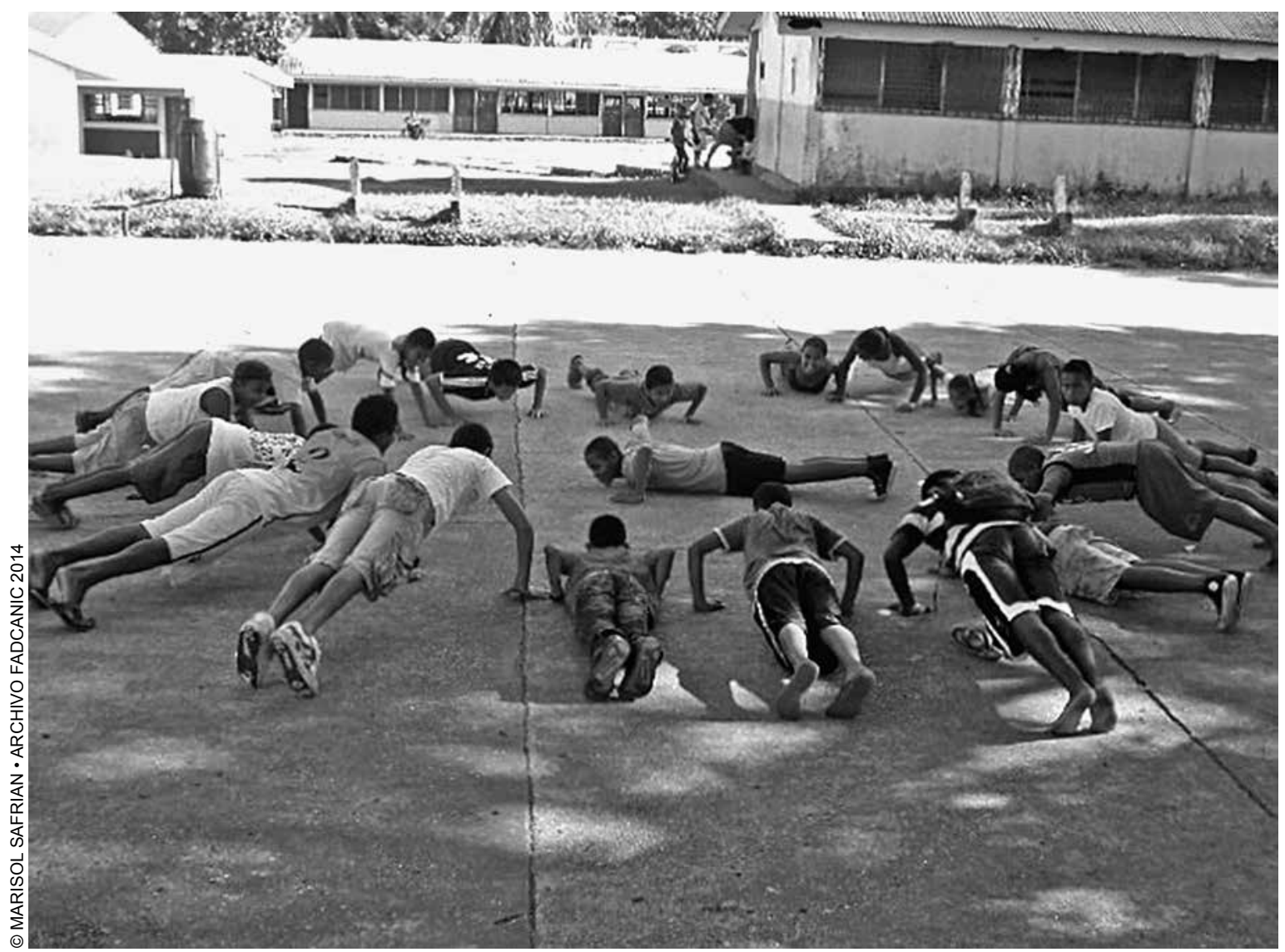

Ejercicios de calentamiento en el Colegio Justo Pastor de Kukra Hill.

- fomentar la realización de ligas escolares, de barrio e intermunicipales.

No menos importante es dotar de materiales deportivos para cada una de las disciplinas que se practican y fomentar proyectos y programas de recreación sana.

Según el estudio, reparar estas infraestructuras tiene un costo estimado de entre US\$175,000 y US\$330,000.

Para conocer en detalle los requerimientos de las infraestructuras deportivas y de recreación identificadas en el municipio de Kukra Hill ver al final del artículo, en Anexos, la Tabla 2.

\section{Laguna de Perlas: mayor parte en buen estado}

El municipio de Laguna de Perlas se encuentra ubicado a $45 \mathrm{Km}$. de la ciudad de Bluefields. Posee una extensión territorial de 3,876 $\mathrm{Kms}^{2}$ y una población estimada en 10 , 676 habitantes. Proyecciones poblacionales al 2014 sitúan la población del municipio en 11,127 habitantes de los cuales el $49 \%$ son mujeres. En términos etarios, del total de la población registrada en el censo de 2005 , el $45 \%$ es menor de 15 años y de este total, el $49 \%$ son mujeres.

El deporte de mayor popularidad es el béisbol, el que es practicado por aficionados. Sin embargo también se practica el baloncesto y el volibol. Hay 14 infraestructuras deportivas y de recreación que en su mayoría están en los centros escolares. El 8\% está en excelente estado, 60\% en buen estado, el $30 \%$ en regular estado y el $2 \%$ en mala condiciones.

En Laguna de Perlas hay dos estadios, uno en la sede municipal y el otro en Orinoco. En el Estadio Municipal Harry \& Maggie Taylor se realizan juegos nocturnos debido a que cuenta con luminarias, así como con graderías. Sin embargo carece de baños públicos, de agua corriente, de equipamiento de seguridad y precisa de mantenimiento y de limpieza.

Se calcula que se podría equipar con estos servicios básicos con una inversión entre US\$10,000 y US\$25,000. 


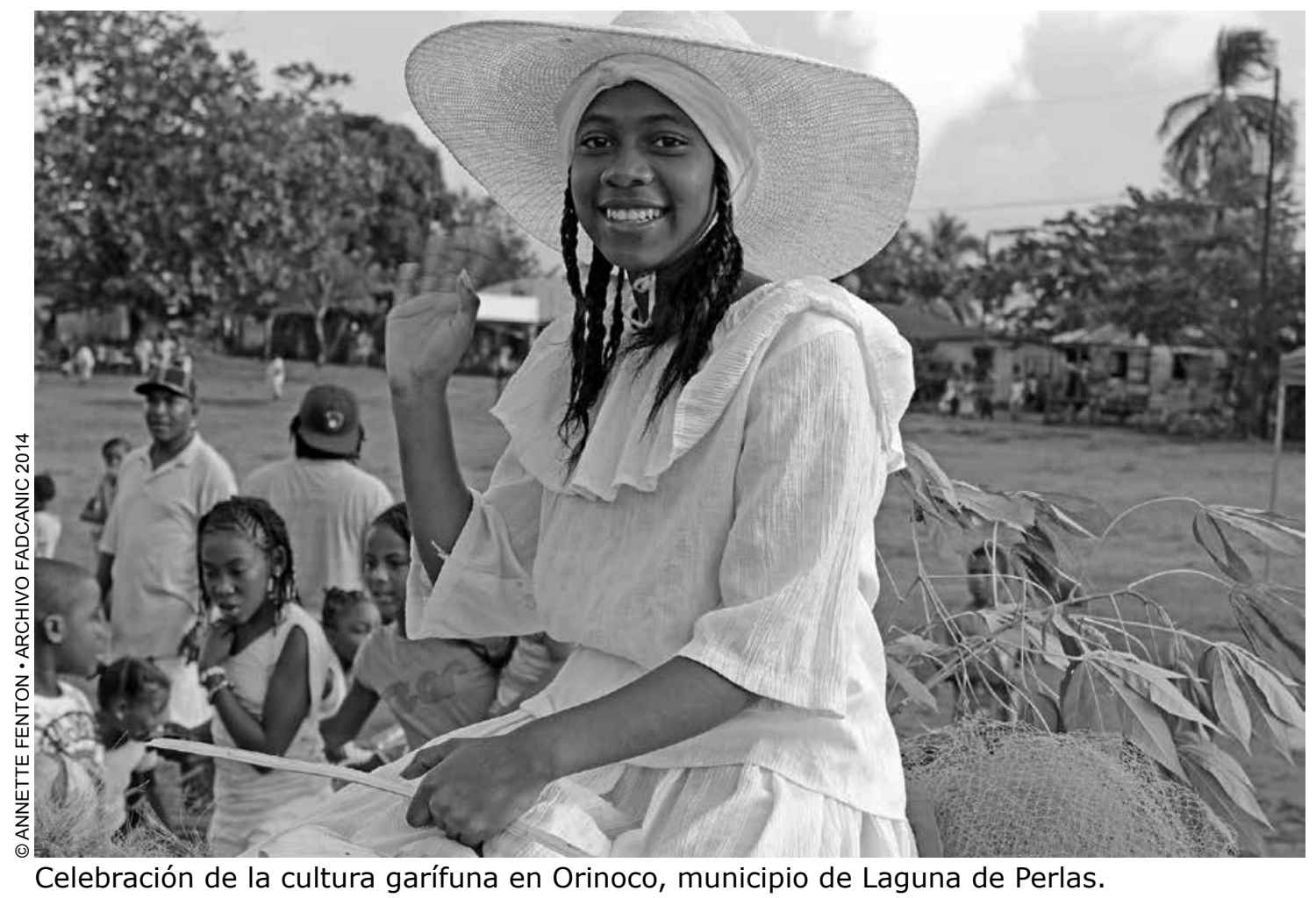

Mientras tanto, el Estadio Mónica Hebbert de Orinoco necesita de sistema eléctrico, entre otras cosas y su rehabilitación podría costar US\$40,000.

En las comunidades de Orinoco, Wawashang y Tasbapouni existen campos de béisbol abiertos, así como canchas de baloncesto y de volibol con condiciones mínimas. De allí, el costo total de las reparaciones de todas las infraestructuras deportivas y culturales en el municipio -que incluyen dos centros integrados de cultura, uno en Laguna de Perlas y otro en la comunidad de Orinocooscila entre US\$410,000 y US\$690,000.

Se destaca también que en Laguna de Perlas existen federaciones de baloncesto y de béisbol organizadas. En el caso de la primera disciplina, anualmente se celebra un torneo de categoría libre en el que participan entre siete y ocho equipos.

Anualmente también se organiza una liga municipal clase Mayor A de béisbol, en el que en promedio participan siete equipos. El ganador participa en el campeonato regional.

Para conocer en detalle los requerimientos de las infraestructuras deportivas y de recreación identificadas en el municipio de Laguna de Perlas ver al final del artículo, en Anexos, la Tabla 3.

\section{Desembocadura: Las iglesias conservan infraestructuras}

El municipio de La Desembocadura se encuentra ubicado a $470 \mathrm{Km}$ de la ciudad de Managua. Posee una extensión territorial de $1,978 \mathrm{Km}^{2}$ y una población estimada en 3,585 habitantes. Proyecciones poblacionales al 2014 sitúan la población del municipio en 3,901 habitantes de los cuales el $50 \%$ son mujeres. En termino etarios, del total de la población registrada en el censo de 2005 , el $43 \%$ es menor de 15 años y de este total, el $22 \%$ son mujeres.

En el municipio de la Desembocadura de la Cruz de Río Grande se identificaron siete infraestructuras de recreación deportivas que están ubicadas en diferentes puntos del municipio, principalmente en sus comunidades y en la cabecera municipal.

El estudio resalta que "estos lugares de recreación deportivos en su mayoría tienen un alta frecuencia de visita, principalmente de jóvenes" y están ubicados en su mayoría en centros escolares. El 5\% está en excelente estado, el $35 \%$ en regular estado y el restante $60 \%$ en buen estado.

Las iglesias moravas, anglicanas y maranatha, que tienen centros deportivos en Sandy Bay y Karawala, conservan sus infraestructuras en buen estado. 


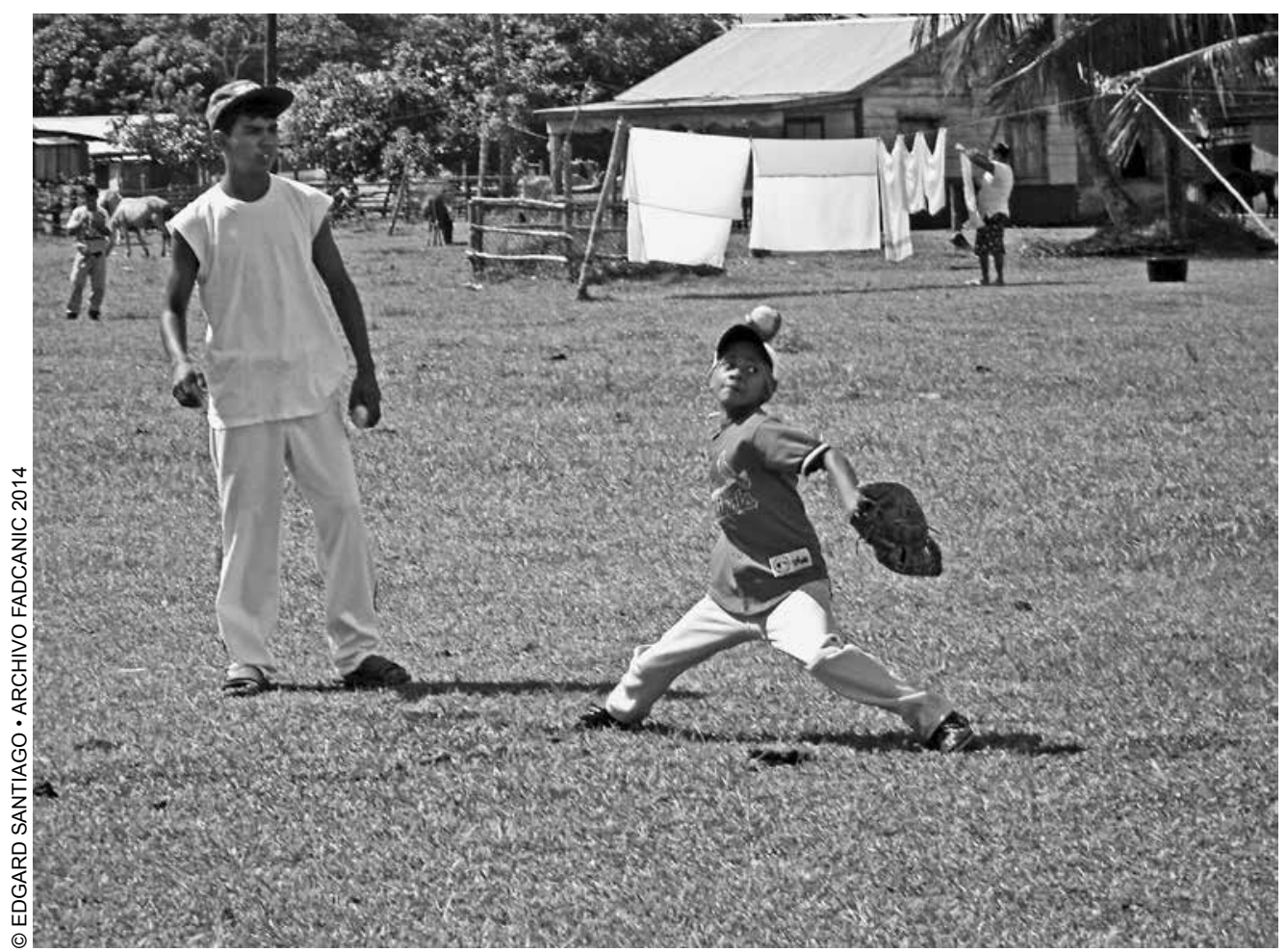

Aprendiendo beisbol en el municipio de Desembocadura de la Cruz de Río Grande.

Los requerimientos de las infraestructuras que están en estado regular son básicamente los mismos: mayor seguridad, mantenimiento, limpieza, luminarias, graderías, baños públicos, entre otros. Una de las infraestructuras más costosas de reparar es el Estadio Municipal Rigoberto Henry Simmons, de la comunidad Karawala, cuya rehabilitación está estimada en US\$100,000.

Para conocer en detalle los requerimientos de las infraestructuras deportivas y de recreación identificadas en el municipio de la Desembocadura de la Cruz de Río Grande ver al final del artículo, en Anexos, la Tabla 4.

\section{Corn Island: En buenas condiciones pero hay que prevenir}

En Corn Island la situación no dista mucho de la de los otros municipios. Los investigadores identificaron 15 infraestructuras deportivas. Ubicadas en su mayoría en terrenos privados, el 5\% está en excelente estado, el 40\% en buen estado, el $50 \%$ en regular estado y $5 \%$ restante en malas condiciones. Como en los otros municipios, incluso las que están en peores condiciones, se ocupan.

El municipio de Corn Island, se encuentra a una distancia de 40 millas en el mar Caribe del municipio de Bluefields. Posee una superficie de $12.5 \mathrm{Km}^{2}$ en la cual según proyecciones de población al 2014 del INIDE habitan un total de 7,394 personas, de las cuales 3,831 son mujeres (52\%). Según datos del Censo de 2005 la población menor de 15 años asciende a un total de 2,444 personas (37\%), de las cuales el $49 \%$ son mujeres.

La principal actividad recreativa es el béisbol. Cada año se celebra en el municipio un campeonato local, cuyo ganador participa en la Serie de Béisbol del Atlántico, la cual rota de sede por cada municipio.

También se practican el baloncesto, el volibol y el softbol, deportes en los que se celebran campeonatos entre barrios y colegios. Asimismo se celebran mensualmente carreras de caballos, como una reminiscencia de las costumbres británicas. A falta de hipódromo, esta actividad se realiza en un camino situado en la parte sur de la Isla Grande.

En la Isla Grande hay un estadio municipal y tres canchas deportivas. En el estadio se pueden realizar actividades nocturnas porque cuenta con luminarias, así como con graderías. Existen tres campos abiertos que son utilizados para jugar béisbol y futbol. Está en construcción un gimnasio multiuso con capacidad para 2,500 personas. En el Barrio BrigBay No. 2 hay un estadio infantil en el que caben 1,000 personas y que según el informe está en buen estado. 
El municipio cuenta con un Centro Integrado de Cultura y una playa (Picnic Center en Southwest Bay) que es visitada todos los días por nativos y extranjeros debido a que presta condiciones para desarrollar actividades de recreación deportiva.

No obstante, "estos centros deportivos y de recreación se encuentran en alto riesgo de mayor deterioro debido a que no cuentan con un presupuesto asignado por la municipalidad y por las autoridades regionales", vuelve a subrayar el informe final. Lasinversiones necesarias en este municipiopodrían rondar entre US\$575,000 y US\$1 millón para instalar luminarias, cercos perimetrales que brinden seguridad a los usuarios, dar mantenimiento y equipar las infraestructuras que aún no cuentan con estos recursos.

Para conocer en detalle los requerimientos de las infraestructuras deportivas y de recreación identificadas en el municipio de Corn Island ver al final del artículo, en Anexos, la Tabla 5.

\section{Inadecuadas para personas discapacitadas}

El estudio reveló que en ninguna de las infraestructuras de los municipios analizados existen condiciones mínimas para que las personas con discapacidad acudan a ellos.

Entre las conclusiones, el equipo investigador determinó que "en los municipios de intervención del Programa EduÉxito, se requiere con prioridad las reparaciones de las canchas multiusos que están dispersas en los barrios y comunidades. Se deben crear al menos las condiciones básicas, como la reparación de los aleros, las luminarias, la construcción de graderías techadas, así como la dotación de equipamientos de los materiales deportivos de las diferentes disciplinas (balones, net de volibol, uniformes, etcétera), que aparecen en los cuadros de requerimientos en las infraestructuras deportivas y de recreación identificadas en cada uno de los municipios".

Por otra parte, la investigación refiere que apenas existe un médico especialista en nutrición en el Hospital Regional de Bluefields, quien no puede atender las demandas en el deporte y asimismo dar seguimiento a los riesgos que se desencadenan en las disciplinas deportivas, en las prácticas y en las competencias. La demanda es tal que también se le dificulta recomendar las dietas alimenticias a seguir.

Cabe destacar que los eventos deportivos son esporádicos y estos no garantizan la calidad de la competencia en los municipios de Región Autónoma del Atlántico Sur.
La principal actividad recreativa es el béisbol, luego, en menor escala, el futbol y se identificó el dominó que es practicado sobre todo por personas adultas. Cada año se celebra un campeonato local de béisbol, cuyo ganador participa en la Serie de Béisbol del Atlántico, la cual rota por cada municipio.

\section{Articulación, políticas y financiamiento}

El gobierno regional de la RACS cuenta con una Secretaría de la Juventud, una entidad que no tiene asignado presupuesto pese a que posee una política en beneficio de la juventud. El estudio también señala que la juventud no se siente representada por las autoridades políticas.

Es importante destacar que es preciso que se dé la articulación interinstitucional entre las diferentes instancias regionales y municipales, como la Secretaría de Educación, Deporte y Juventud; el Ministerio de Salud; la Policía Nacional, el INJUDE y el IND. Este último debe funcionar como ente deportivo regulador que fortalezca la recreación sana en las diferentes disciplinas deportivas.

Así como garantizar la participación de la mayor parte de la población en programas deportivos y de recreación, los investigadores recomiendan en el estudio vincular a la comunidad en la gestión del deporte, la planeación, control y mantenimiento de los bienes, de tal forma "que el tema deportivo y de recreación se implante en la cultura municipal como una esfera vital del desarrollo humano".

Asimismo, los atletas y personas que practican deportes con regularidad deben ser actores fundamentales en la toma de decisiones. La labor educativa es una herramienta primordial en el proceso de transformación sociocultural, por tal razón los investigadores insisten en que las municipalidades deben considerar entre sus prioridades esenciales, la recreación de la juventud e incorporar partidas presupuestarias, así como orientar a la unidad de proyecto que trabajen más en satisfacer las necesidades de las infraestructuras deportivas y de recreación.

Un aspecto fundamental es la búsqueda de fuentes de financiamiento. Las municipalidades y sus comisiones de deporte deben buscar asesoría externa en el tema de la búsqueda de fuentes de financiación nacional e internacional para gestionar proyectos y programas de recreación deportiva y conseguir recursos.

La necesidad de gestionar recursos externos reviste de especial importancia. Los investigadores hicieron 
hincapié en que la elaboración e implementación de un plan estratégico que recoja las necesidades, permitirá una optimización de los recursos y una mayor viabilidad.

\section{Baja participación}

Se evidencia un bajo nivel de participación de la población en las diversas alternativas deportivas y recreativas. La principal causa es la falta de materiales deportivos y de conocimiento e información sobre los programas que se ofrecen. Aunque la mayor parte de la población sabe que el deporte es un derecho constitucional, no participan en los procesos de planeación deportiva, ya que no son tomados en cuenta.

En general, el estudio resalta que el acceso a los escenarios deportivos, recreativos y de educación física son libres. Solamente los escenarios de educación física tienen un porcentaje de restricción medio-bajo, debido a que son utilizados exclusivamente por los estudiantes.

En las recomendaciones del estudio se señala que los municipios deben realizar exhibiciones de talentos propios o externos en las diferentes modalidades deportivas, recreativas, artísticas y culturales. Sugieren "impulsar deportes exequibles y de interés para la población; incrementar la oferta de actividades relacionadas con el medio ambiente; ofrecer juegos tradicionales como el billar, las cartas, el dominó, juegos con un enfoque lúdico, sin alcohol y sin apuestas de dinero; así como impulsar los deportes tradicionales con un enfoque lúdico, como las carreras de caballos, las montadas de toros, sin sacrificio o maltrato al animal".

Los autores finalmente advierten que estudios recientes realizados por el Banco Mundial y el Programa de Naciones Unidas para el Desarrollo (PNUD), han dado una campanada de alerta, ya que más del $30 \%$ de la población está padeciendo sobrepeso y más de un $12 \%$ de obesidad, lo que está provocando en la población caribeña complicaciones de salud, produciendo problemas cardiovasculares (CVD) e hipertensión. Las causas de este fenómeno son las disposiciones genéticas, el fuerte consumo energético de "comida chatarra", el escaso gasto energético por la falta de ejercicios físicos y mentales en actividades deportivas y de recreación. Urge un cambio en los estilos de vida de adolescentes y jóvenes de la región Caribe, pero para ello falta dar un primer paso, rehabilitar y equipar las infraestructuras deportivas.

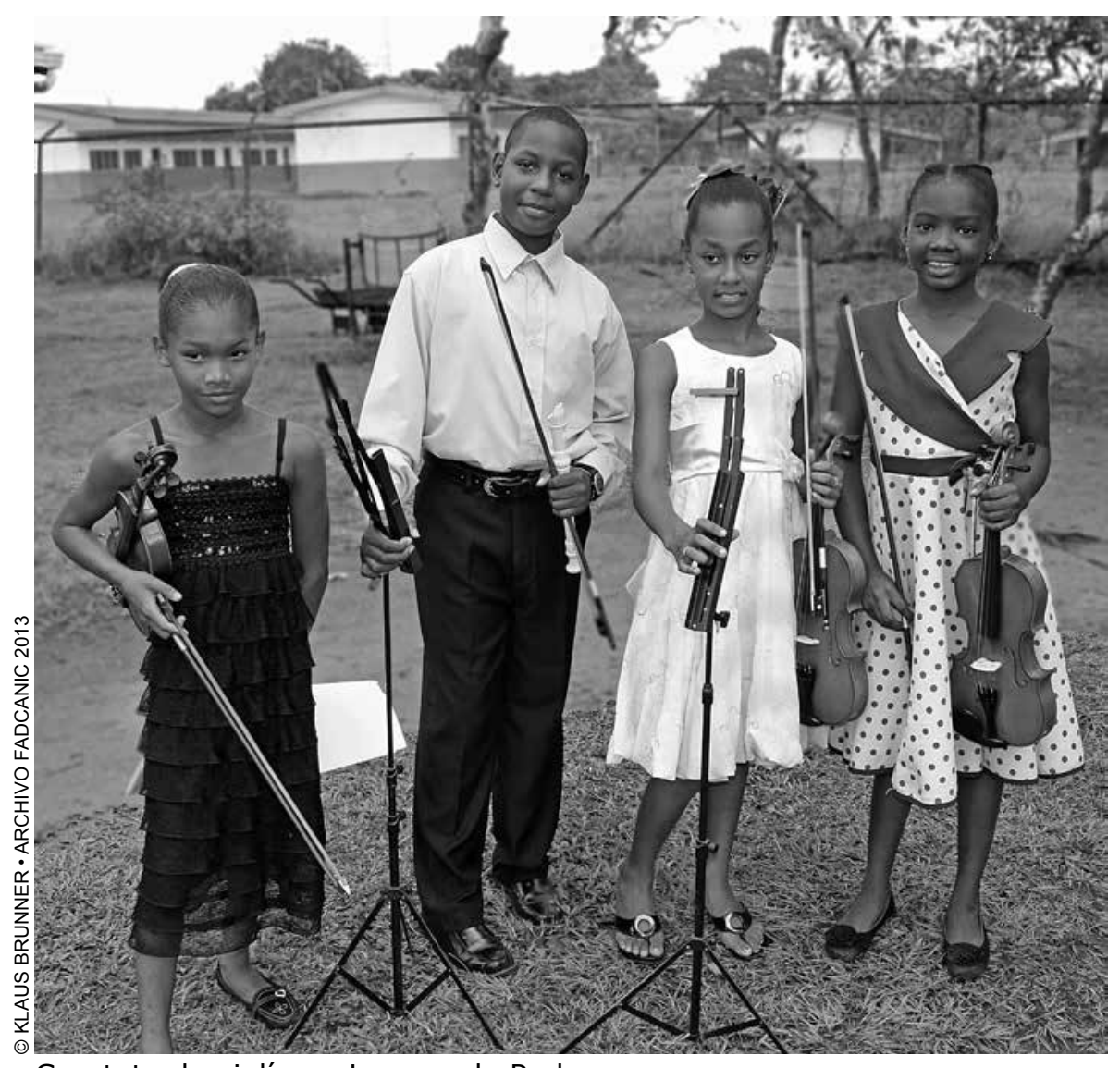

Cuarteto de violín en Laguna de Perlas. 
Becarios de EduÉxito en la cancha de la Escuela Normal de Bluefields.

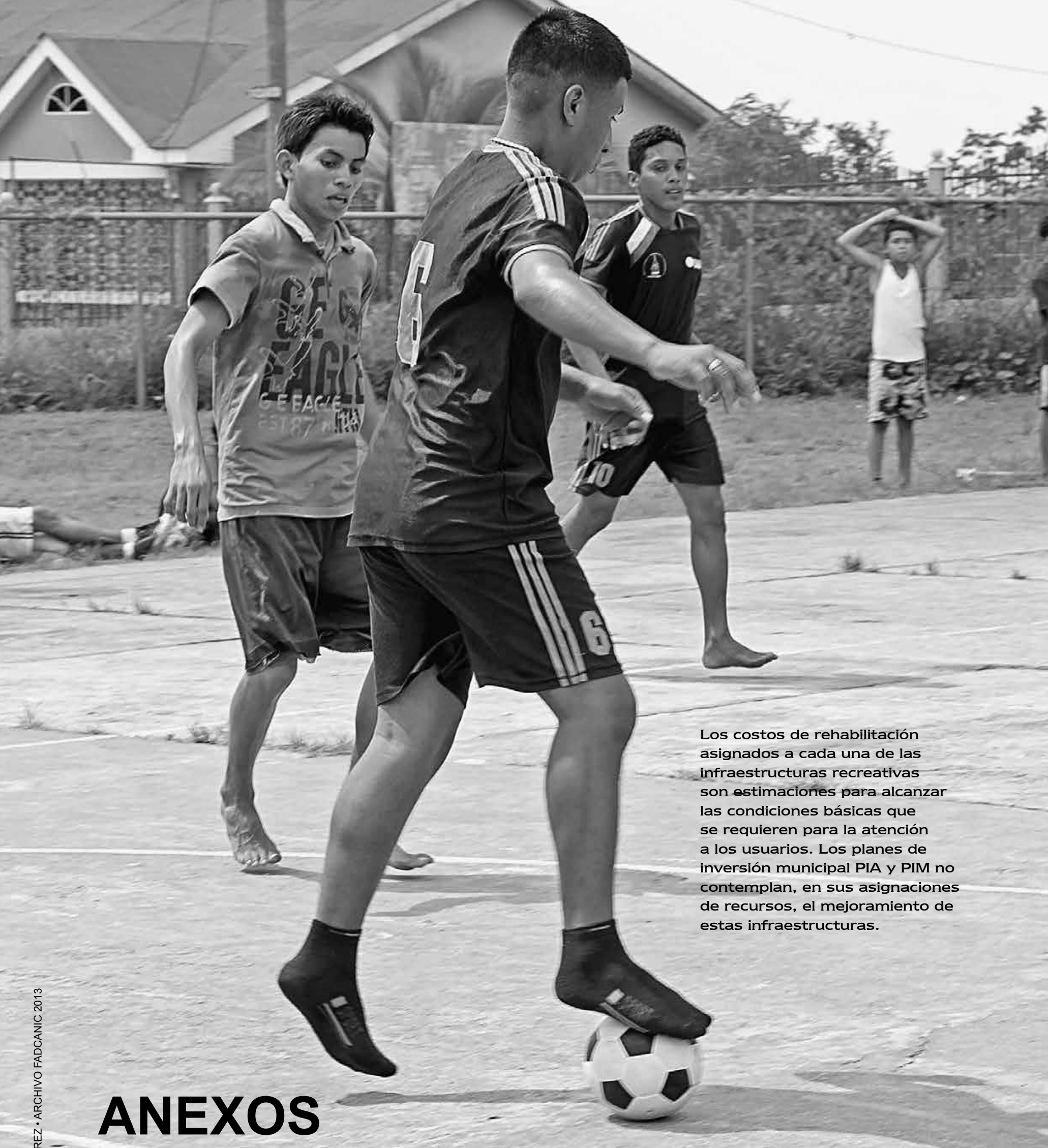

Requerimientos en Tás infraestructuras deportivas y de recreación identificadas en los cinco municipios en que se desarrolla el Programa EduÉxito 


\section{Tabla 1. Requerimientos en las infraestructuras deportivas y de recreación en el municipio de Bluefields}

\begin{tabular}{|c|c|c|}
\hline Nombre de Infraestructura & Requerimiento & $\begin{array}{c}\text { Costo de } \\
\text { Rehabilitación US\$ }\end{array}$ \\
\hline \multicolumn{3}{|c|}{ Bluefields } \\
\hline Parque Reyes & Más iluminación, mayor seguridad (CPF), baños públicos y agua, mantenimiento frecuente, más depósito de basura y materiales de recreación deportivos. & $20,000-50,000$ \\
\hline Cancha multiuso BICU & Revestir el piso, restructuración de los aros, área perimetral con malla, gradería en el sector sur-este, materiales de recreación deportivos. & $30,000-50,000$ \\
\hline Cancha multiuso New York & $\begin{array}{l}\text { Elevar la altura los cables eléctricos y de los servicios de cable y ENITEL, construir bancas y enmallar el área perimetral, depósitos de basura, materiales de } \\
\text { recreación deportiva, baño público. }\end{array}$ & $3,500-5,000$ \\
\hline Cancha multiuso Teodoro Martínez & $\begin{array}{l}\text { Desramar los árboles que afectan la luminosidad, mejorar el sistema de aguas negras que pasa al costado de la misma y e levar la altura de los cables en ese } \\
\text { sector, depósitos de basura, materiales de recreación deportiva, baño público. }\end{array}$ & $2,000-4,000$ \\
\hline Cancha multiuso URACCAN & Rehabilitarla para que brinde las condiciones requeridas, depósitos de basura, materiales de recreación deportiva, baño público. & $20,000-60,000$ \\
\hline Estadio de Baseball & Construir la barda, poner luminarias, baños, sistema de agua, depósitos de basura, materiales de recreación deportivas y baño público. & $30,000-50,000$ \\
\hline Cancha multiuso Asentamiento Cubano & $\begin{array}{l}\text { Dotar de balones, graderías con techo, depósitos de basura, mejorar el sistema de luminarias y el enmallado, mantenimiento, materiales de recreación } \\
\text { deportiva, baño público. }\end{array}$ & $2,000-5,000$ \\
\hline Cancha multiuso Punta Fría & $\begin{array}{l}\text { Más seguridad (casos de asalto, jóvenes portando armas de fuego, venta y consumo de droga), poner malla en vez de angulares en la parte baja y después } \\
\text { malla en la parte alta, para evitar que las pelotas estén afectando las viviendas situadas en el contorno de la cancha, tableros con su aro, techo a las bancas, } \\
\text { recipientes para basura, materiales de recreación deportivas, baño público. }\end{array}$ & $5,000-12,000$ \\
\hline $\begin{array}{l}\text { Parquecito Punta Fría, donde fue el } \\
\text { Rastro Municipal. }\end{array}$ & $\begin{array}{l}\text { Malla perimetral, luminarias, seguridad (CPF), los andenes son muy lisos en la bajada, baños y sistema de agua, las ruinas del anterior matadero pueden } \\
\text { derrumbarse y afectar el área de juego de los niños, basureros. }\end{array}$ & $5,000-8,000$ \\
\hline $\begin{array}{l}\text { Cancha multiuso } \\
\text { Esc. Menorca }\end{array}$ & $\begin{array}{l}\text { Muro perimetral, reparar el aro del tablero de baloncesto, mejorar el muro que está en mal estado del Colegio Divino Pastor, recipientes de basura, } \\
\text { materiales deportivos, baño público. }\end{array}$ & $10,000-20,000$ \\
\hline $\begin{array}{l}\text { Cancha multiuso Gimnasio } \\
\text { Colegio Divino Pastor }\end{array}$ & Baño, gradería y servicio de agua. & No determinado \\
\hline Cancha multiuso Gimnasio (IND) & $\begin{array}{l}\text { lluminación externa, baños y sistema de agua, seguridad (CPF), muro con mayor seguridad, rehabilitar el por ciento de la infraestructura que falta, } \\
\text { recipientes para basura, materiales deportivos, baño público. }\end{array}$ & $20,000-50,000$ \\
\hline $\begin{array}{l}\text { Gimnasio deportivo multiuso Instituto } \\
\text { Colón }\end{array}$ & Proyecto formulado y en gestión para su construcción (En manos del MINED y la Dirección del Colegio Cristóbal Colón), materiales deportivos. & $200,000-250,000$ \\
\hline Gimnasio deportivo multiuso INATEC & $\begin{array}{l}\text { Mantenimiento y ampliación del sistema eléctrico, graderías, instalación permanente de tableros y aros, porterías y construir bases para tubos de red de } \\
\text { voleibol, señalizaciones y agua (grifos-servicios higiénicos), recipientes para basura. }\end{array}$ & $50,000-80,000$ \\
\hline Cancha multiuso & $\begin{array}{l}\text { Brindar mayor seguridad (casos de asalto de jóvenes portando armas de fuego, venta y consumo de droga), angulares (en vez de malla), y en la parte alta } \\
\text { poner malla para evitar que las pelotas afecten a las viviendas del contorno de la infraestructura, gradería con techo, luminarias, recipientes para basura, } \\
\text { baño público y materiales deportivos. }\end{array}$ & $30,000-60,000$ \\
\hline Gimnasio de baloncesto & Falta de seguridad, más luminarias, cerco perimetral, recipientes para basura, materiales deportivos y baño público. & $25,000-50,000$ \\
\hline Estadio Glorias Costeñas & Construir nuevamente el estadio, luminarias y recipientes para basura. & $350,000-700,000$ \\
\hline Malecón Santa Rosa & $\begin{array}{l}\text { Luminarias, construir bancas con techo y glorieta que brinde servicios a turistas, materiales de recreación deportiva, baño público y agua, cerco perimetral, } \\
\text { baños y sistema de agua, y recipientes para basura. }\end{array}$ & $30,000-50,000$ \\
\hline Campo Deportivo Loma Fresca & $\begin{array}{l}\text { Faltan: muro perimetral, seguridad, luminarias, baños, sistema de agua, } \\
\text { recipientes para basura. También requiere movimiento de tierra y suministro de materiales deportivos. }\end{array}$ & $20,000-40,000$ \\
\hline Quinta Tres Hermanas & $\begin{array}{l}\text { Construir juegos para niños, mejorar el servicio en la piscina (agua de mejor calidad-más recambio), brindar servicios de comida y refrigerios. Equipamiento } \\
\text { de materiales deportivos, construir quioscos de descanso, colocar recipientes para basura, edificar baños y establecer sistema de agua. Mantener botiquín } \\
\text { de primeros auxilios. Brindar mayor seguridad en el perímetro. }\end{array}$ & $8,000-15,000$ \\
\hline Centro Recreativo Bethel & Equipamiento de materiales deportivos, botiquín de primeros auxilios, servicios básicos de aguay electricidad, & $3,000-7,000$ \\
\hline Cancha multiuso Colegio Verbo & Equipamiento de materiales deportivos, botiquín de primeros auxilios, recipientes para basura, servicios básicos de agua, electricidad y baño. & $5,000-10,000$ \\
\hline Centro Integrado de Cultura Regional & Finalizar la construcción del Centro, instrumentos y materiales para promocionar las actividades culturales, seguridad, más iluminación y servicios básicos. & $150,000-200,000$ \\
\hline Cancha multiuso & $\begin{array}{l}\text { Rehabilitar la cancha multiuso, muro perimetral, luminarias, materiales deportivos, graderías con techo, mejorar área de acceso (andenes), recipientes para } \\
\text { basura. }\end{array}$ & $15,000-25,000$ \\
\hline Gimnasio multiuso Colegio Moravo & Mejorar el sistema eléctrico y de iluminación, mantenimiento de graderías, materiales deportivos, recipientes para basura, botiquín de primeros auxilios. & $40,000-70,000$ \\
\hline Cancha multiuso Colegio San José & Datación de materiales deportivos, recipientes para basura, botiquín de primeros auxilios, mejorar el sistema eléctrico y de iluminación. & $15,000-35,000$ \\
\hline Cancha multiuso Escuela Normal & Gradería con techo, luminarias, mantenimiento a la infraestructura, materiales deportivos, recipientes para basura, botiquín de primeros auxilios. & $10,000-20,000$ \\
\hline Cancha multiuso Colegio Betesta & Rehabilitar la cancha, materiales deportivos, recipientes para basura, botiquín de primeros auxilios. & $12,000-18,000$ \\
\hline \multirow[t]{2}{*}{ Campo Deportivo } & Gradería con techo, pizarra electrónica, luminarias, materiales deportivos, recipientes para basura, botiquín de primeros auxilios. & $80,000-130,000$ \\
\hline & Rama Kay & \\
\hline Centro Comunitario de Cultura Rama Kay & Rehabilitar el CCC y ponerlo en las condiciones óptimas para brindar un servicio de calidad a los usuarios. Todos los servicios básicos. & $20,000-30,000$ \\
\hline \multicolumn{3}{|c|}{ El Bluff } \\
\hline Estadio multiuso Puerto El Bluff & Muro de seguridad, drenaje, agua, reparación de grama, luminarias y CPF & $80,000-130,000$ \\
\hline Cancha de Básquet Instituto Nuevo Amanecer & Reparar aros y luminarias, construir techo, muro perimetral, baños y sistema de agua. Habilitar materiales deportivos, mayor seguridad (CPF). & $12,000-18,000$ \\
\hline Cancha multiuso Pista Aérea & Reparar aros y luminarias, construir techo, muro perimetral, baños y sistema de agua, mayor seguridad (C.P.F), habilitar materiales deportivos. & $12,000-18,000$ \\
\hline Parque Central El Bluff & Juego de recreación Infantil, limpieza, baños públicos y agua, alumbrado público y mayor seguridad (C.P.F). & $10,000-12,000$ \\
\hline Cancha de Básquet Sector \#4 & Reemplazo & $20,000-25,000$ \\
\hline Playa Bluff Big & Limpieza, materiales de recreación deportiva, baños públicos, agua y seguridad. & $100,000-120,000$ \\
\hline
\end{tabular}

Fuente: FADCANIC 2013 


\section{Tabla 2. Requerimientos en las infraestructuras deportivas y de recreación en el municipio de Kukra Hill}

\begin{tabular}{|c|c|c|}
\hline Nombre de Infraestructura & Requerimiento & Costo de rehabilitación US $\$$ \\
\hline Cancha deportiva & $\begin{array}{l}\text { Luminarias, sistema eléctrico, material deportivo, baño público y agua, mantenimiento (limpieza y pintura), reparación } \\
\text { de aro, revestimiento de concreto, muro perimetral y gradas, seguridad (C.P.F). }\end{array}$ & $40,000-70,000$ \\
\hline Estadio Edwin Omier Puchie & $\begin{array}{l}\text { Levantado de la barda de los fílders, pizarra electrónica, materiales deportivos, baño y agua, mantenimiento del } \\
\text { terreno, seguridad (C.P.F.) }\end{array}$ & $25,000-50,000$ \\
\hline Gimnasio multiuso & $\begin{array}{l}\text { Reemplazo de techo, materiales deportivos, sistema eléctrico baño y agua, mantenimiento (pintura y limpieza), } \\
\text { construcción de muro perimetral, }\end{array}$ & $20,000-40,000$ \\
\hline Campo alterno de Beisbol & $\begin{array}{l}\text { Rehabilitación del terreno y movimiento de tierra, equipamiento de material deportivo, baño y agua, alumbrado } \\
\text { público, seguridad (C.P.F.), construcción de muro perimetral. }\end{array}$ & $30,000-60,000$ \\
\hline Campo de Futbol & $\begin{array}{l}\text { Rehabilitación del terreno y movimiento de tierra; baño y agua, alumbrado público, equipamiento de materiales } \\
\text { deportivos, seguridad (C.P.F.), construcción de muro perimetral }\end{array}$ & $30,000-60,000$ \\
\hline Casa de Cultura & $\begin{array}{l}\text { Cielo raso, baño y agua, sistema eléctrico, pintura, equipamiento de materiales deportivos, alumbrado público, } \\
\text { seguridad (C.P.F.). }\end{array}$ & $10,000-15,000$ \\
\hline $\begin{array}{l}\text { Cancha Colegio Padre Hugo } \\
\text { Heinseng }\end{array}$ & $\begin{array}{l}\text { Luminaria y sistema eléctrico, reparación de aro, equipamiento de materiales deportivos, revestimiento de concreto, } \\
\text { baño público y agua, mantenimiento (limpieza y pintura), muro perimetral y gradas, seguridad (C.P.F). }\end{array}$ & $20,000-35,000$ \\
\hline
\end{tabular}

Fuente: FADCANIC 2013.

\section{Tabla 3. Requerimientos en las infraestructuras deportivas y de recreación en Laguna de Perlas}

\begin{tabular}{|c|c|c|}
\hline Nombre de Infraestructura & Requerimientos & $\begin{array}{l}\text { Costo de rehabilitación } \\
\text { en US\$ }\end{array}$ \\
\hline \multicolumn{3}{|c|}{ Laguna de Perlas } \\
\hline Cancha Comunal & $\begin{array}{l}\text { Luminarias y sistema eléctrico, baño público y agua, seguridad (C.P.F), mantenimiento (limpieza y pintura), muro } \\
\text { perimetral y gradas, reparación de aro, revestimiento de concreto, equipamiento de materiales deportivos. }\end{array}$ & $40,000-70,000$ \\
\hline Casa de Cultura & $\begin{array}{l}\text { Muro perimetral y gradas, baño público y agua, equipamiento de materiales deportivos, mantenimiento (limpieza y } \\
\text { pintura), seguridad (C.P.F). }\end{array}$ & $20,000-35,000$ \\
\hline $\begin{array}{l}\text { Estadio Municipal } \\
\text { Harry \& Maggy Taylor }\end{array}$ & Baño público y agua, materiales deportivos, mantenimiento (limpieza y pintura), seguridad (C.P.F). & $10,000-25,000$ \\
\hline Gimnasio multiuso & Reemplazo del alumbrado público, equipamiento de materiales deportivos, baños y agua. & $90,000-140,000$ \\
\hline Cancha Colegio Beulah Lightburn & $\begin{array}{l}\text { Luminaria y sistema eléctrico, reparación de aro, revestimiento de concreto, equipamiento de materiales deportivos, } \\
\text { baño público y agua, mantenimiento (limpieza y pintura), muro perimetral y gradas, seguridad (C.P.F). }\end{array}$ & $25,000-40,000$ \\
\hline \multicolumn{3}{|c|}{ Haulover } \\
\hline Cancha deportiva & $\begin{array}{l}\text { Luminarias y sistema eléctrico, reparación de aro, equipamiento de materiales deportivos, revestimiento de concreto, } \\
\text { baño público, mantenimiento (limpieza y pintura). muro perimetral y gradas, seguridad (C.P.F). }\end{array}$ & $30,000-50,000$ \\
\hline Campo deportivo & Luminarias y sistema eléctrico, revestimiento de tierra, baño público y agua, & $30,000-50,000$ \\
\hline \multicolumn{3}{|c|}{ Orinoco } \\
\hline Casa de Cultura & Luminarias, mantenimiento (limpieza y pintura), materiales deportivos, muro perimetral y gradas, seguridad (C.P.F.). & $20,000-40,000$ \\
\hline Estadio Mónica Hebberth & $\begin{array}{l}\text { Luminarias y sistema eléctrico, baño público y agua, mantenimiento (limpieza y pintura), materiales deportivos, repa- } \\
\text { ración de muro, construcción de gradas, seguridad (C.P.F.). }\end{array}$ & $25,000-40,000$ \\
\hline Cancha deportiva & $\begin{array}{l}\text { Luminarias y sistema eléctrico, baño público y agua, mantenimiento (limpieza y pintura), muro perimetral y gradas, } \\
\text { seguridad (C.P.F), materiales deportivos. }\end{array}$ & $30,000-50,000$ \\
\hline $\begin{array}{l}\text { Cancha y campo recreativo Centro de } \\
\text { Educación Ambiental y Agroforestal }\end{array}$ & $\begin{array}{l}\text { Luminarias y sistema eléctrico, baño público y agua, mantenimiento (limpieza y pintura), muro perimetral y gradas, } \\
\text { equipamiento de materiales deportivos seguridad (C.P.F). }\end{array}$ & \\
\hline \multicolumn{3}{|c|}{ Tasbapauni } \\
\hline Cancha Deportiva & $\begin{array}{l}\text { Luminarias, sistema eléctrico, reparación de aro, revestimiento de concreto, baño público y agua, mantenimiento } \\
\text { (limpieza y pintura), muro perimetral y gradas, materiales deportivos, seguridad (C.P.F). }\end{array}$ & $30,000-50,000$ \\
\hline Campo deportivo abierto & $\begin{array}{l}\text { Luminarias y sistema eléctrico, revestimiento y movimiento de tierra, baño público y agua, mantenimiento (limpieza y } \\
\text { pintura), muro perimetral y gradas, seguridad (C.P.F), materiales deportivos. }\end{array}$ & $30,000-50,000$ \\
\hline Escuela Tasbapauni & $\begin{array}{l}\text { Luminarias, sistema eléctrico, reparación de aro, revestimiento de concreto, baño público y agua, mantenimiento } \\
\text { (limpieza y pintura), muro perimetral y gradas, seguridad (C.P.F), materiales deportivos. }\end{array}$ & $30,000-50,000$ \\
\hline
\end{tabular}

Fuente: FADCANIC 2013. 


\section{Tabla 4. Requerimientos en las infraestructuras deportivas y de recreación en el municipio Desembocadura de la Cruz de Río Grande}

\begin{tabular}{|c|c|c|}
\hline Nombre de Infraestructura & Requerimientos & Costo de rehabilitación US\$ \\
\hline \multicolumn{3}{|c|}{ Sandy Bay } \\
\hline Preescolar Ejam Smith & $\begin{array}{l}\text { Luminarias, sistema eléctrico, baño y agua, mantenimiento (limpieza y pintura), muro perimetral, juegos recreativos, } \\
\text { seguridad (C.P.F.), materiales deportivos, botiquín de primeros auxilios. }\end{array}$ & $30,000-50,000$ \\
\hline Esc. Primaria Ejam Smith & $\begin{array}{l}\text { Baños y agua, mantenimiento (limpieza y pintura), reparación sistema eléctrico, materiales deportivos, botiquín de } \\
\text { primero auxilio, seguridad (C.P.F.). }\end{array}$ & $15,000-30,000$ \\
\hline Instituto Johnny Hooker & $\begin{array}{l}\text { Baños y agua, concluir la infraestructura, mantenimiento (limpieza y pintura), seguridad (C.P.F.). muro perimetral, } \\
\text { materiales deportivos, cancha deportiva de concreto de multiuso, botiquín de primeros auxilios. }\end{array}$ & $20,000-30,000$ \\
\hline Iglesia Morava madera & Alumbrado público, sistema eléctrico, materiales deportivos, & $5,000-10,000$ \\
\hline $\begin{array}{l}\text { Campo Deportivo Comunal Junior } \\
\text { Charles Rubén }\end{array}$ & $\begin{array}{l}\text { Luminarias y sistema eléctrico, materiales deportivos, movimiento de tierra, baño público y agua, mantenimiento } \\
\text { (limpieza y pintura), muro perimetral y gradas, seguridad (C.P.F.). }\end{array}$ & $90,000-150,000$ \\
\hline Parque Infantil Howard Netan & $\begin{array}{l}\text { Luminarias y sistema eléctrico, juegos recreativos, seguridad (C.P.F.), baño público y agua, materiales deportivos, } \\
\text { mantenimiento (limpieza y pintura). }\end{array}$ & $20,000-35,000$ \\
\hline Iglesia Morava concreto & $\begin{array}{l}\text { Luminarias y sistema eléctrico, mantenimiento (limpieza y pintura) } \\
\text { equipamiento de materiales deportivos }\end{array}$ & $8,000-15,000$ \\
\hline $\begin{array}{l}\text { Iglesia Anglicana } \\
\text { Comunidad }\end{array}$ & Luminarias, baño público y agua, mantenimiento (limpieza y pintura). materiales deportivos. & $8,000-15,000$ \\
\hline Playa Sandy Bay & $\begin{array}{l}\text { Luminarias y sistema eléctrico, baño público y agua, mantenimiento (limpieza y pintura), construcción de kioscos de } \\
\text { descanso, seguridad (C.P.F.), materiales deportivos, botiquín de primeros auxilios. }\end{array}$ & $30,000-50,000$ \\
\hline Iglesia Maranatha & Luminarias y sistema eléctrico, mantenimiento (limpieza y pintura), materiales deportivos. & $8,000-15,000$ \\
\hline Casa Municipal de Cultura & $\begin{array}{l}\text { Concluir la construcción de la infraestructura, luminarias y sistema eléctrico, } \\
\text { baño público y agua, mantenimiento (limpieza y pintura), botiquín de primeros auxilios, materiales deportivos. } \\
\text { seguridad (C.P.F.). }\end{array}$ & $30,000-70,000$ \\
\hline \multicolumn{3}{|c|}{ Karawala } \\
\hline $\begin{array}{l}\text { Estadio Municipal } \\
\text { Rigoberto Henry Simons }\end{array}$ & $\begin{array}{l}\text { Luminarias y sistema eléctrico, reparación del terreno y la gradería, materiales deportivos, construcción de pizarra, } \\
\text { baño público y agua, mantenimiento (limpieza y pintura), seguridad (C.P.F.). }\end{array}$ & $70,000-100,000$ \\
\hline $\begin{array}{l}\text { Iglesia de Dios } \\
\text { Comunidad Karawala }\end{array}$ & Luminarias y sistema eléctrico, baño público y agua, mantenimiento (limpieza y pintura). & $8,000-15,000$ \\
\hline Instituto Ulwas & $\begin{array}{l}\text { Luminarias y sistema eléctrico, baño público y agua, mantenimiento (limpieza y pintura), materiales deportivos, } \\
\text { botiquín de primeros auxilios, seguridad (C.P.F.). }\end{array}$ & $15,000-30,000$ \\
\hline Escuela Primaria Valdivio Gómez & $\begin{array}{l}\text { Luminarias, sistema eléctrico, baño público y agua, mantenimiento (limpieza y pintura), materiales deportivos, } \\
\text { botiquín de primeros auxilios, seguridad (C.P.F.). }\end{array}$ & $15,000-30,000$ \\
\hline $\begin{array}{l}\text { Campo deportivo comunitario } \\
\text { pista aérea }\end{array}$ & $\begin{array}{l}\text { Luminarias y sistema eléctrico, baño público y agua, mantenimiento (limpieza y pintura), materiales deportivos, } \\
\text { botiquín de primeros auxilios. }\end{array}$ & $15,000-30,000$ \\
\hline Iglesia Maranatha & Luminarias y sistema eléctrico, baño público, mantenimiento (limpieza y pintura). & $8,000-15,000$ \\
\hline Iglesia Anglicana & $\begin{array}{l}\text { Luminarias y sistema eléctrico, baño público y agua, materiales deportivos de recreación, mantenimiento (limpieza } \\
\text { y pintura). }\end{array}$ & $8,000-15,000$ \\
\hline $\begin{array}{l}\text { Casa de Consejo de Anciano } \\
\text { Auditorio }\end{array}$ & $\begin{array}{l}\text { Luminarias y sistema eléctrico, baño público y agua, mantenimiento (limpieza y pintura), materiales deportivos, } \\
\text { botiquín de primeros auxilios, materiales deportivos. }\end{array}$ & $15,000-30,000$ \\
\hline Iglesia Morava & Luminarias y sistema eléctrico, mantenimiento (limpieza y pintura). & $8,000-15,000$ \\
\hline Parque infantil & rehabilitación total, luminarias y sistema eléctrico, materiales deportivos de recreación. & $60,000-80,000$ \\
\hline Muelle Municipal & Luminarias y sistema eléctrico, baño público y agua, mantenimiento (limpieza y pintura), seguridad (C.P.F.). & $15,000-30,000$ \\
\hline \multicolumn{3}{|c|}{ La Barra } \\
\hline Cancha Comunal & Rehabilitación total, todos los servicios básicos, luminarias y sistema eléctrico, materiales deportivos de recreación. & $60,000-80,000$ \\
\hline Campo Deportivo & $\begin{array}{l}\text { Luminarias y sistema eléctrico, materiales deportivos de recreación, baño público y agua, gradería y entechado, } \\
\text { muro perimetral, mantenimiento (limpieza y pintura), seguridad (C.P.F.). }\end{array}$ & $80,000-12,0000$ \\
\hline
\end{tabular}

Fuente: FADCANIC 2013. 


\section{Tabla 5. Requerimientos en las infraestructuras deportivas y de recreación en el municipio de Corn Island}

\begin{tabular}{|c|c|c|}
\hline Nombre de Infraestructura & Requerimientos & $\begin{array}{l}\text { Costo de Rehabilitación en } \\
\text { US\$ }\end{array}$ \\
\hline Parque Brig Bay 1 & $\begin{array}{l}\text { Luminaria, baño, mantenimiento (limpieza y pintura), juegos recreativos, materiales, deportivos, botiquín de } \\
\text { primeros auxilios, seguridad (C.P.F). }\end{array}$ & $70,000-100,000$ \\
\hline $\begin{array}{l}\text { Cancha Brig Bay } 1 \\
\text { Campo abierto }\end{array}$ & $\begin{array}{l}\text { Baños, mantenimiento (limpieza y pintura), reparación del sistema eléctrico, seguridad (C.P.F). materiales } \\
\text { deportivos, botiquín de primeros auxilios, }\end{array}$ & $20,000-30,000$ \\
\hline $\begin{array}{l}\text { Cancha South End } \\
\text { Campo abierto }\end{array}$ & $\begin{array}{l}\text { Baños, concluir la infraestructura, mantenimiento (limpieza y pintura), seguridad (C.P.F). muro perimetral, } \\
\text { materiales eportivos, } \\
\text { botiquín de primeros auxilios, }\end{array}$ & $40,000-70,000$ \\
\hline $\begin{array}{l}\text { Picnic Center. S.A } \\
\text { Cancha y playa }\end{array}$ & Alumbrado público, materiales deportivos, baño público, seguridad (C.P.F). & $8,000-15,000$ \\
\hline $\begin{array}{l}\text { Arena Beach } \\
\text { Cancha y playa abierto }\end{array}$ & Luminaria, materiales deportivos, baño público, mantenimiento (limpieza y pintura), seguridad (C.P.F). & $10,000-25,000$ \\
\hline Escuela Primaria Nubia Rigby Patio & $\begin{array}{l}\text { Luminaria, juegos recreativos, seguridad (C.P.F). baño público, mantenimiento (limpieza y pintura), área de } \\
\text { recreación. }\end{array}$ & $15,000-30,000$ \\
\hline $\begin{array}{l}\text { Escuela Primaria Oliver Brown } \\
\text { Cancha, campo abierto }\end{array}$ & Luminaria, rehabilitación de la cancha deportiva, mantenimiento (limpieza y pintura), & $25,000-50,000$ \\
\hline $\begin{array}{l}\text { Campo Deportivo abierto privado de } \\
\text { Futbol y Beisbol }\end{array}$ & Luminarias, mantenimiento (limpieza y pintura), botiquín de primeros auxilios, materiales deportivos, & $10,000-25,000$ \\
\hline $\begin{array}{l}\text { Cancha Deportiva de Volibol y } \\
\text { Baloncesto } \\
\text { Abierto a todo público }\end{array}$ & $\begin{array}{l}\text { Luminarias, construcción de gradas y entechado, baño público, } \\
\text { mantenimiento (limpieza y pintura), seguridad (C.P.F). materiales deportivos, botiquín de primeros auxilios. }\end{array}$ & \\
\hline $\begin{array}{l}\text { Escuela primaria Rigoberto Cabezas } \\
\text { campo para estudiante }\end{array}$ & Luminarias, materiales deportivos, mantenimiento (limpieza y pintura). & $10,000-25,000$ \\
\hline $\begin{array}{l}\text { Escuela primaria Bautista Ebenecer } \\
\text { centro privado campo de estudiantes }\end{array}$ & $\begin{array}{l}\text { Construcción de la infraestructura deportiva, gimnasio multiuso, } \\
\text { mantenimiento (limpieza y pintura), botiquín de primer auxilio, materiales deportivos, seguridad (C.P.F). }\end{array}$ & $100,000-180,000$ \\
\hline $\begin{array}{l}\text { Instituto Nacional Alba Hooker Downs } \\
\text { campo de estudiantes }\end{array}$ & $\begin{array}{l}\text { Luminarias, reparación de terreno, construcción de gimnasio, baño público, mantenimiento (limpieza y pintura), } \\
\text { seguridad (C.P.F). }\end{array}$ & $100,000-180,000$ \\
\hline $\begin{array}{l}\text { Cancha multiuso de Baloncesto, } \\
\text { Vólibol, futbol sala, } \\
\text { Campo abierto a todo Publico }\end{array}$ & $\begin{array}{l}\text { Luminarias, construcción de gradas y techado, baño público, mantenimiento (limpieza y pintura), seguridad } \\
\text { (C.P.F). materiales deportivos, botiquín de primeros auxilios. }\end{array}$ & $50,000-80,000$ \\
\hline $\begin{array}{l}\text { Parque Infantil Brig Bay } \\
\text { Abierto a todo público }\end{array}$ & $\begin{array}{l}\text { Luminaria, baño público, mantenimiento (limpieza y pintura), materiales deportivos, botiquín de primero auxilio, } \\
\text { seguridad (C.P.F). }\end{array}$ & $30,000-50,000$ \\
\hline Casa Municipal de Cultura & $\begin{array}{l}\text { Luminarias, baño público, mantenimiento (limpieza y pintura), materiales recreativos, botiquín de primeros } \\
\text { auxilios, seguridad (C.P.F). }\end{array}$ & $30,000-50,000$ \\
\hline $\begin{array}{l}\text { Estadio Municipal Karen Tucker } \\
\text { Abierto a todo público }\end{array}$ & mantenimiento (limpieza y pintura), materiales deportivos, botiquín de primeros auxilios, & $7,000-12,000$ \\
\hline $\begin{array}{l}\text { Estadio Infantil campo alterno } \\
\text { Abierto a todo público }\end{array}$ & Luminarias, baño público, mantenimiento (limpieza y pintura), & $10,000-25,000$ \\
\hline $\begin{array}{l}\text { Campo de Futbol } \\
\text { Abierto a todo público }\end{array}$ & Luminarias, baño público, mantenimiento (limpieza y pintura). & $10,000-25,000$ \\
\hline $\begin{array}{l}\text { Gimnasio multiuso Municipal } \\
\text { Para todo público }\end{array}$ & Luminaria, baño público, mantenimiento (limpieza y pintura), botiquín de primero auxilio, materiales deportivos. & $10,000-25,000$ \\
\hline $\begin{array}{l}\text { Iglesia Morava } \\
\text { Miembros de la Iglesia }\end{array}$ & Luminarias, mantenimiento (limpieza y pintura), & $10,000-15,000$ \\
\hline $\begin{array}{l}\text { Cancha y Parque } \\
\text { Abierto a todo público }\end{array}$ & Luminarias, sistema eléctrico, baño público, mantenimiento (limpieza y pintura), seguridad (C.P.F). & $10,000-25,000$ \\
\hline Parque la Loma & Luminarias, sistema eléctrico, baño público, mantenimiento (limpieza y pintura), seguridad (C.P.F). & $10,000-25,000$ \\
\hline
\end{tabular}

Fuente: FADCANIC 2013. 